\title{
MEASUREMENT AND MODELING OF SUSPENDED SEDIMENT DYNAMICS IN WATERCOURSES
}

\author{
JANJA KRAMER STAJNKO, RENATA JECL \& MATJAŽ NEKREP PERC \\ Faculty of Civil Engineering, Transportation Engineering and Architecture, University of Maribor, Slovenia
}

\begin{abstract}
The problem of sedimentation in surface waters has considerable implications for environmental protection, but also for the use of hydropower on the watercourse and for long-term planning of flood risk management and water management. For an efficient management of suspended sediments, it is necessary to carry out appropriate measurements in order to maintain the quantity and dynamics of sediment movement as a function of changing hydraulic conditions. The data collected on site are the input for the development of a suitable model that can be used to establish a long-term plan for sediment management and to calibrate the numerical models. The paper presents an analysis of suspended sediment measurements in a Slovenian river. A correlation between concentration and discharge was investigated, especially during flood event. The suspended sediment dynamics depends on energy conditions, i.e. material is transported during high discharge events and deposited during low flow. The model of the suspended sediment concentration is a function of the water runoff and the amount of sediment deposition. Different models should be used at low discharge and at high discharge to correctly predict the amount of transported sediment concentrations. When modelling flood events, an additional sediment supply term should be added to the rating curve.
\end{abstract}

Keywords: suspended sediment dynamics, hysteresis loop, watercourses, rating curve.

\section{INTRODUCTION}

The transport of suspended sediment in watercourses is initiated by precipitation and runoff which are the main erosion agents causing the detachment of weathered surface material on the upper layer of the earth's crust and the movement of this material along the channel. The dynamics of suspended matter in watercourses generally depends on the energy conditions, i.e. the material in rivers moves at high discharge and is stored at low discharge. Furthermore, the transport rates are also a function of sediment availability [1].

Suspended sediment in the watercourse represent most of all material that moves along the stream and is crucial for siltation of river profiles, flood-prone areas, and surface waters (lakes, seashore). The amount of transported material depends on the current discharge, since the higher discharge causes stronger turbulent forces on the solid particles and thus a larger amount of suspended matter moving along the watercourse. On the other hand, if the flow rate is low, the transport capability is reduced, and the material begins to settle on the river bottom and along the riverbanks. It has been proven that the amount of sediment in the watercourse depends on climatic changes, glacier melt and intensive erosion processes, which result in larger amounts of material. The transport dynamics as well as the quantity of material are also influenced by human interventions in the riverbed, e.g. by the construction of hydropower plants and other hydraulic structures. The result of the material transport is the filling up of the reservoirs and the riverbed, which reduces the natural cycle of water circulation due by weakening drainage into the aquifers.

The deposition of sediments on the riverbanks is particularly problematic during floods, as they are deposited on the flood plains and in the surrounding area. Both adsorbed organic and inorganic substances occur on the sediment particles, which can lead to chemical pollution of the flooded areas. Furthermore, it has been proven that the damage caused by floods is significantly higher at higher sediment concentrations in the water than in clear 
water. Indeed, the material deposited on the flooded areas reduces the ability of the returning tidal wave to cause greater damage.

When observing the dependence between the suspended sediment concentrations and the discharge, hysteresis loops are observed which can be divided into five types [2]: singlevalues (straight or curved) relation, clockwise (positive) loop, counter-clockwise (negative) loop, single-values plus a loop and figure eight. Hysteresis loops are indicating the offset of suspended sediment concentrations from the discharge peaks which can be used to explain different locations of sediment source areas within the catchment area.

To describe the relationship between the suspended sediment concentration and water discharge, empirical models are often applied. The most commonly used model is a rating curve in the form of a power function as obtained in Walling [3], Kolár [4] and Ismail [5], where two empirically derived regression coefficients are included. The accuracy of the rating curve model is often low which is due to variations in sediment supply and depletion which result in hysteresis effects. Therefore, alternative models have been developed by adding parameters that represents sediment supply - the-so-called "supply-based model" [1].

In the present paper an analysis of a single hydrological event in October 2018 on the Drava River is performed with identification and classification of $C-Q$ relation. A typical anti-clockwise hysteresis loop occurred based on which the location of sediment sources can be predicted.

\section{STUDY AREA}

The study focuses on the section of the Drava River near the town Maribor. The Drava is the second largest river in Slovenia and a tributary of the Danube. It has its source in South Tyrol, in Italy. The river flows through Austria, Slovenia and Croatia and after its confluence with its main tributary the Mura, it forms the largest part of the border between Croatia and Hungary before it joins the Danube at Osijek. The length of the Drava in Slovenia is $117.7 \mathrm{~km}$, the catchment area is $4,662 \mathrm{~km}^{2}$ and the average discharge is $292 \mathrm{~m}^{3} / \mathrm{s}$. The main tributaries in Slovenia are the Meža $\left(12 \mathrm{~m}^{3} / \mathrm{s}\right)$ and the Dravinja $\left(11 \mathrm{~m}^{3} / \mathrm{s}\right)$. The Drava is one of the most exploited rivers in the world in terms of hydropower, with almost $100 \%$ of its water potential energy being exploited. There are 22 hydropower plants on the Drava, eight of them in Slovenia which have a strong influence on the dynamics of suspended sediment in the watercourse.

Continuous discharge measurements have been carried out at each individual hydropower plant, while turbidity measurements to determine suspended matter concentrations have been carried out at four locations along the river section in Slovenia.

The investigation of suspended sediment concentration on Drava River during high water event end of October 2018 was carried out at the Duplek Bridge (Fig. 1), which is located between the cities of Maribor and Ptuj. In this part of the river, the outflow channel is separated from the Drava riverbed at the Melje dam to supply the Zlatoličje power plant, which was built during years 1964 and 1969. The maximum capacity of the derivation channel is $500 \mathrm{~m}^{3} / \mathrm{s}$. When the capacity of the derivation channel is reached, the excess of the water flows in the (natural) river bed. The required ecological river discharge in this area is $10 \mathrm{~m}^{3} / \mathrm{s}$ in winter (from 15 October to $15 \mathrm{March}$ ) and $20 \mathrm{~m}^{3} / \mathrm{s}$ in summer (from $15 \mathrm{March}$ to 15 October).

\section{SUSPENDED SEDIMENT SAMPLING}

The high-water event in autumn 2018 began on 29/10/2018, when the discharge of the river Drava exceeded the value of $500 \mathrm{~m}^{3} / \mathrm{s}$. The discharge in the (natural) riverbed began to 


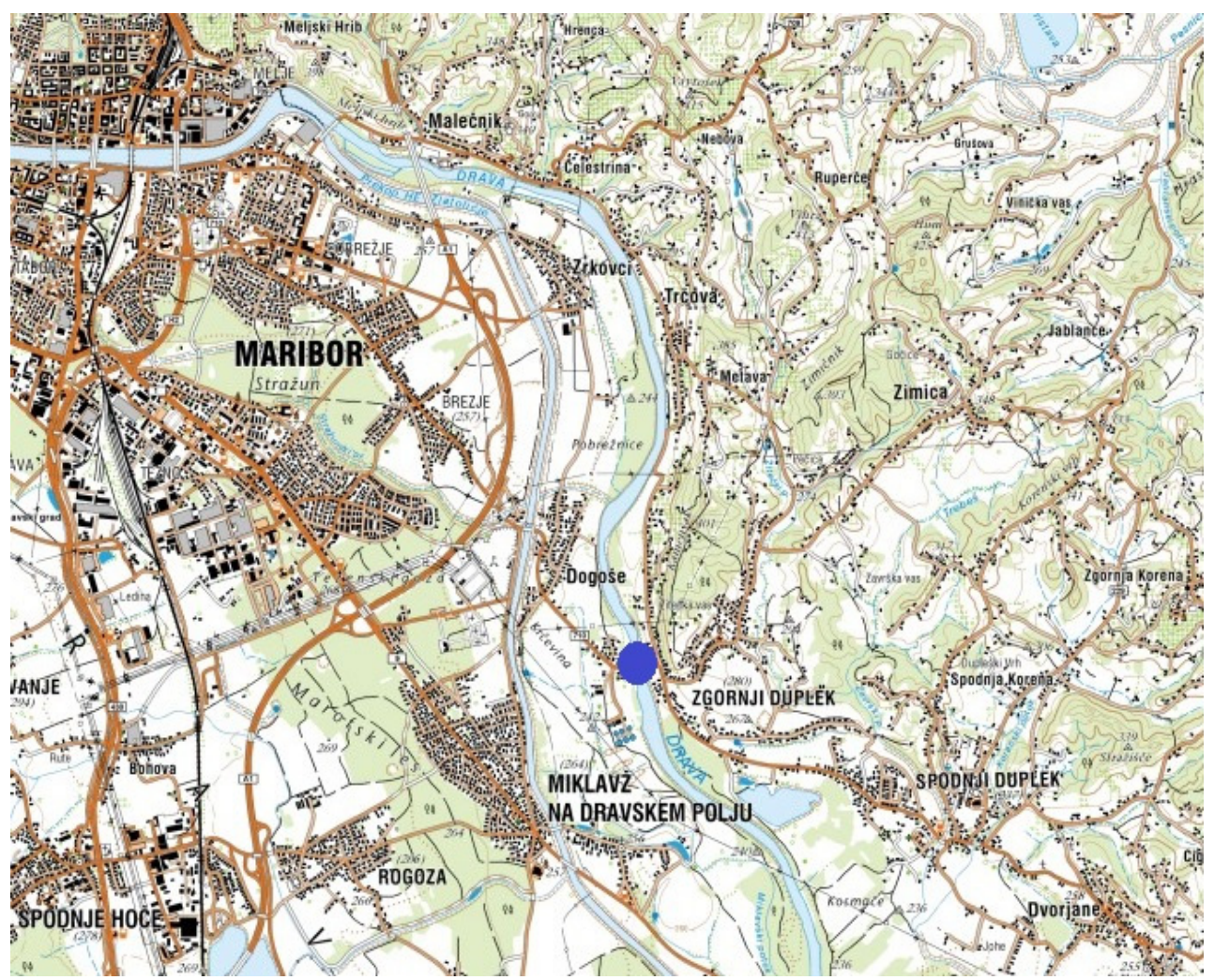

Figure 1: Location of water sampling in The Drava River (Duplek bridge).

increase from $10 \mathrm{~m}^{3} / \mathrm{s}$; the maximum measured discharge was $1,391 \mathrm{~m}^{3} / \mathrm{s}$. The discharge values above $1,000 \mathrm{~m}^{3} / \mathrm{s}$ lasted for three days; after 31/10/2018 the discharge began to decrease.

The real-time discharge data were collected from the automatic measuring station at the Melje dam from on the premises of Dravske elektrarne (DEM) - operators of hydropower plants on Drava River - and are available online at all times.

In order to determine the concentration of suspended sediment as a function of discharge during high water event the water samples were collected manually from the bridge in $1,000 \mathrm{ml}$ plastic sample bottles. The water samples were taken at a discharge of $796 \mathrm{~m}^{3} / \mathrm{s}$. The samples were collected at one- or two-hour intervals depending on the increasing dynamics of the discharge. The samples were collected until the $4 / 11 / 2018$, whereas during in the last four days (when the values of the discharge were less than $500 \mathrm{~m}^{3} / \mathrm{s}$ and decreased significantly) only one sample per day was collected.

Afterwards the water samples were filtered through glass microfiber filters, while the suspended sediment concentration was determined according to the standard SIST EN 872:2005 (Water quality - Determination of suspended solids - Method by filtration through glass fiber filters). The filter papers were dried in an oven and weighted with RADWAG AS 220.R2 Analytical Balance. 


\section{RESULTS}

The results of the measured values of suspended sediment concentrations are shown in Fig. 2, in addition, the $C-Q$ relationship is shown in Fig. 3. It can be observed that suspended sediment concentrations on the rising limb are lower than on the falling limb at equivalent flows, which results in a counter-clockwise or anti-clockwise hysteresis loop where the $C$ peak arrives later than $Q$ peak. The ratio $C_{1} / Q_{1}\left(C_{1}\right.$ is the read of the concentration at the discharge $Q_{1}$ on the rising limb) is significantly lower than $C_{2} / Q_{1}\left(C_{2}\right.$ is the read of the concentration at the same discharge $Q_{1}$ on the falling limb).
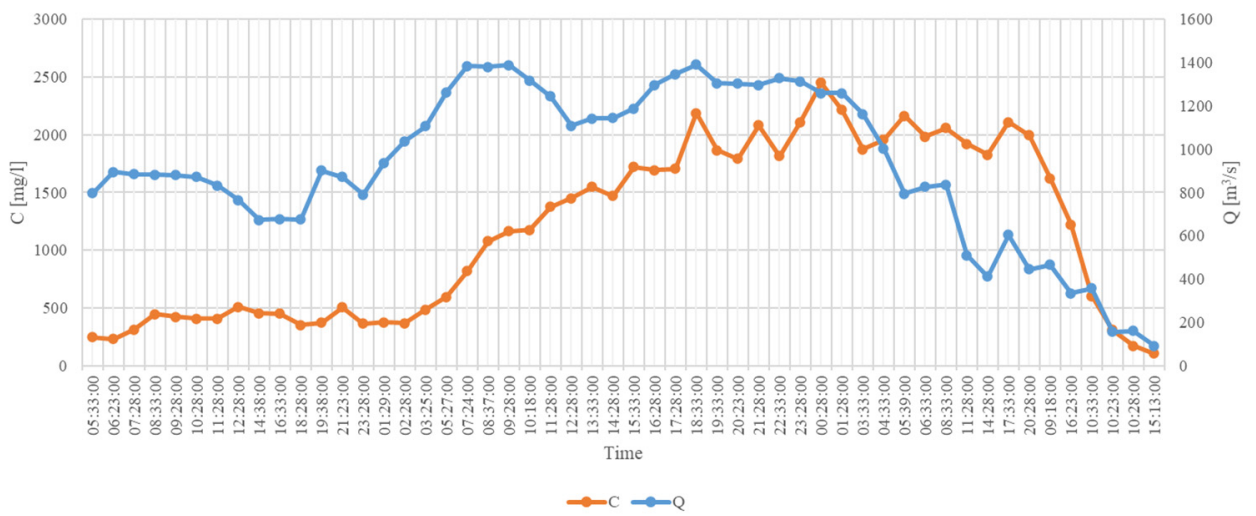

Figure 2: $\quad$ Time evolution of the discharge $Q$ and suspended sediment concentrations $C$ for the high-water event in October 2018 on the Drava River.

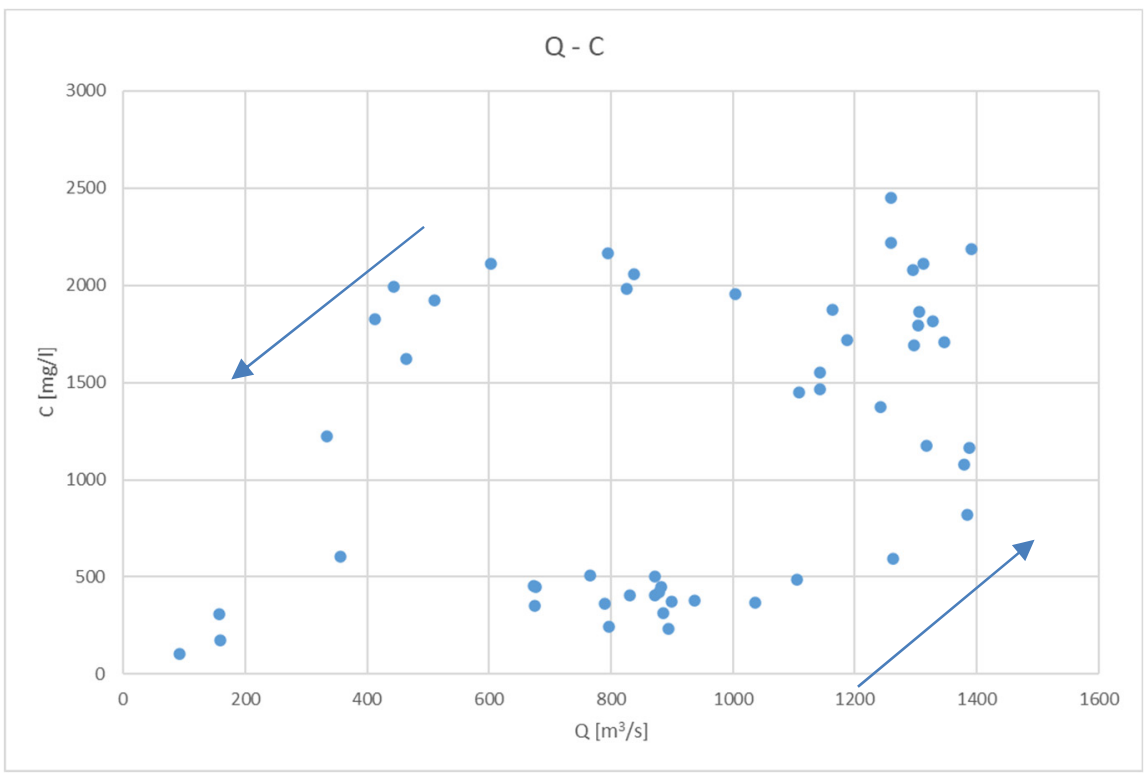

Figure 3: Relationship between suspended sediment concentrations and water discharge for the high-water event in October 2018 on the Drava River. 
There are three possible causes for the loops of this class as reported in Asselman [1] and Williams [2]:

1. Relative travel times of the flood wave and the sediment flux in view of the downstream distance between the flood source and the measuring location. The sediment flux is transported with the delay relatively on the flood wave, while the delay time increases with the distance downstream. The delay in sediment peaks normally occurs in watercourses with irregularities that inhibit the movement of sediment relative to the water.

2. High soil erosion capacity combined with long lasting erosion during floods.

3. Seasonal variability of precipitation distribution and sediment production within the catchment area.

\section{SUSPENDED SEDIMENT MODELING}

To quantify erosion processes and suspended sediment dynamics, empirical relationships between suspended sediment concentration and water discharge are often used. A rating curve in the form of a power function is the most commonly used relationship as reported in Walling [3], Kolár [4] and Ismail [5]:

$$
C=a Q^{b},
$$

where $C$ is the suspended sediment concentration in $m g / l ; Q$ is the water discharge in $\mathrm{m}^{3} / \mathrm{s}$; and $a$ and $b$ are empirically derived regression coefficients. The accuracy of the sediment rating curve is often low, which is related to the scatter of the suspended sediment concentration values around the regression line. This can be attributed, among others, to variations in sediment availability which results in the hysteresis effects.

The values of the parameters $a$ and $b$ were obtained using the data for the rising limb of the hydrograph resulting in $a=6.89 \times 10^{-5}$ and $b=2.337$ (Fig. 4).

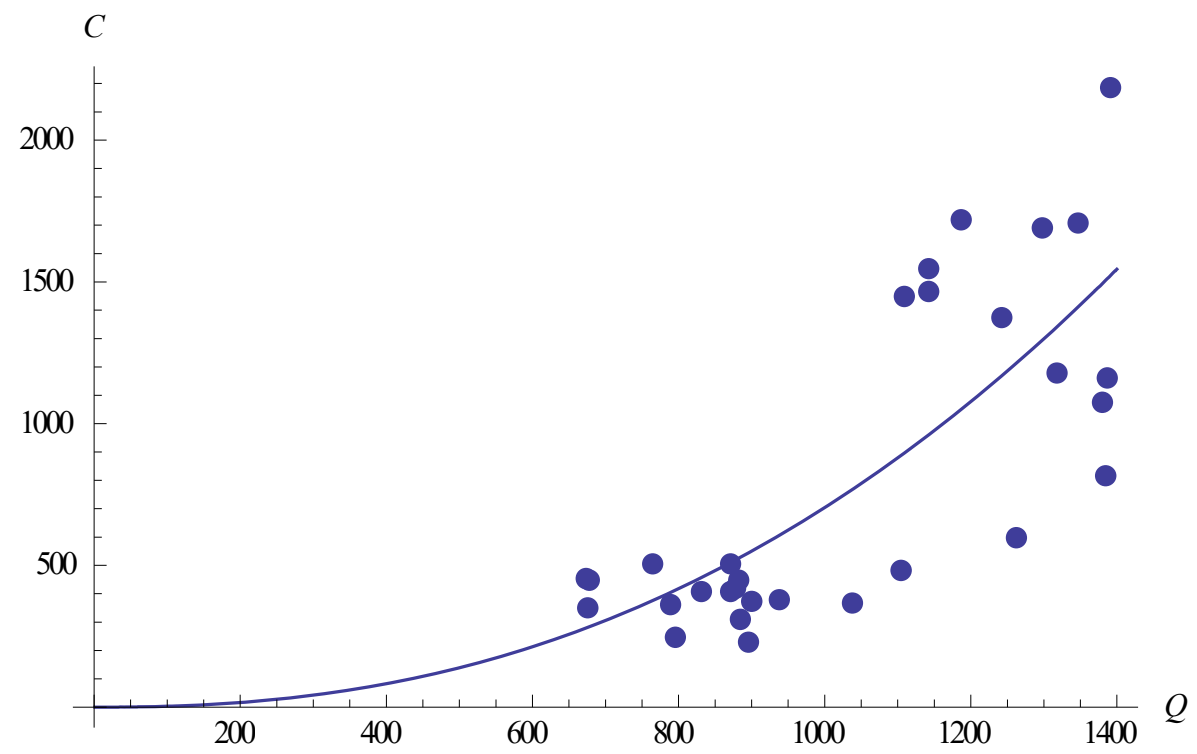

Figure 4: A rating curve in a form of power function (1) for the rising limb of hydrograph where the estimates of the parameter values are $a=6.89 \times 10^{-5}$ and $b=2.337$. 
Several extensions of the general suspended sediment dynamics model have been developed and can be found in the literature. One of the possibilities, to get more accurate model of suspended sediment dynamics and to investigate the influence of sediment supply and sediment depletion on a scatter around the regression line is to separate the discharge wave into the base and direct flow. In this case the suspended sediment concentration associated with the direct runoff is calculated separately from the suspended sediment concentration during the base flow. Suspended sediment concentration during the base flow do not change with the discharge and remains low, as reported in Bača [6].

A possible extension of the model based on the rating curve is a supply-based model, developed by VanSickle and Beschta [7], which includes sediment transport as a function of water discharge and the amount of sediment storage. It takes into account the variation in sediment availability during flood, which result in different sediment concentrations during the rising and falling limb of the hydrograph. Therefore, the rating curve model is supplemented with the sediment supply function as follows:

$$
C(t)=a Q(t)^{b} g[S(t)],
$$

where $g[S(t)]$ is sediment supply function and can be computed according to VanSickle and Beschta [7] as:

$$
g[S(t)]=p e^{\left(\frac{r}{S_{0}}\right) S(t)}
$$

where $S_{0}$ is the initial amount of sediment available for transport at the beginning of the hydrological year, in $\mathrm{kg}$, and $S(t)$ is the suspendable material remaining in the stream channel at the time $t$ later during runoff season, in $\mathrm{kg}$, and $p$ and $r$ are dimensionless calibration parameters that are determined empirically. Parameter $r$ represents the sensitivity of the site for hysteresis effects.

The recorded data of the high-water event in October 2018 were used to calibrate the model. The value of $r / S_{0}$ was estimated by the expression [1]:

$$
\frac{C\left(t_{B}\right)}{C\left(t_{A}\right)}=e^{\left\{\frac{r}{S_{0}}\left[S\left(t_{B}\right)-S\left(t_{A}\right)\right]\right\}},
$$

where $A$ and $B$ are selected points at equal discharge on the rising and falling limb of the hydrograph respectively, $C\left(t_{A}\right)$ and $C\left(t_{B}\right)$ are concentrations at equal discharge. The estimates of parameter values are $r / S_{0}=4.33 \times 10^{-10}$ and $p=2.423$.

The accuracy of the model is rated with the $R^{2}$, as defined in Nash and Sutcliffe [8]. In the case of the model with rating curve the efficiency and is $R^{2}=0.36$ in the case of supply based model, the efficiency, which is $R^{2}=0.85$, indicates better efficiency of the supply based model, where the differences in sediment concentrations during the flood is taken into account. However, the model should be validated using data of several high discharge events on the selected location in order to accurate determine the variations in sediment supply and sediment depletion.

\section{CONCLUSION}

Suspended sediment dynamics during high-water event in Drava river in Slovenia was investigated in order to estimate the correlation between the concentration of suspended matter and water discharge. The sediment availability plays a significant role besides the energy conditions which results in a hysteresis effect indicating different values of suspended sediment concentrations on the rising limb of a storm hydrograph than on the falling limb at equivalent discharge. An anti-clockwise or counter-clockwise hysteresis loop was observed 
in the case of a flood event on the Drava river where the suspended sediment concentration was significantly higher on the falling limb than on the rising limb of the hydrograph. This phenomenon indicates that the sediment sources are located at the far end of the area that contributes to surface runoff. The delay of high values of the sediment concentration in the water can also be a consequence of bank collapse during a high discharge wave. However, further investigations, e.g. about the land use, vegetation cover, rainfall intensity would be necessary to determine the exact origin of the sediments.

The suspended sediment concentrations during high discharge events can be modelled with the rating curve, which should be supplemented with the additional sediment supply term, taking into account changing values of deposited sediments. The results of the studied high-water event show better accuracy of the model with an additional supply term that of the rating curve and therefore more realistic view on the suspended sediment dynamics in watercourse during high-water event. However, in order to obtain a more accurate model of $C-Q$ relation, several consecutive discharge events at the same location should be considered.

\section{REFERENCES}

[1] Asselman, E.M.N., Suspended sediment dynamics in a large drainage basin: The River Rhine. Hydrological Processes, 13, pp. 1437-1450, 1999.

[2] Williams, G.P., Sediment concentration versus water discharge during single hydrologic events in rivers. Journal of Hydrology, 111(1-4), pp. 89-106, 1989.

[3] Walling, D.E., Suspended sediment and solute yields from a small catchment prior to urbanisation. Fluvial Processes in Instrumented Watersheds, pp. 169-192, 1974.

[4] Kolár, V., Reconnaissance measurements and sediment yield estimates in basins with insufficient data. Erosion and Solid Matter Transport in Inland Waters, 122, pp. 3-10, 1977.

[5] Ismail, W.R., The hydrology and sediment yield of the Sungai Air Terjun catchment, Penang Hill, Malaysia. Hydrological Sciences Journal, 45(6), pp. 897-910, 2000.

[6] Bača, P., Hysteresis effect in suspended sediment concentration in the Rybárik basin, Slovakia. Hydrological Sciences Journal, 53(1), pp. 224-235, 2008.

[7] VanSickle, J. \& Beschta, R.L., Supply-based models of suspended sediment transport in streams. Water Resources Research, 19, pp. 768-778, 1983.

[8] Nash, J.E. \& Sutcliffe, J.V., River flow forecasting through conceptual models Part I a discussion of principles. Journal of Hydrology, 10, pp. 282-290, 1970. 